\title{
Preparation of a Carbon-Based Solid Acid with High Acid Density via a Novel Method
}

\author{
Siyu Ouyang, Xiangming Kuang, Qiong Xu, Dulin Yin \\ National \& Local Joint Engineering Laboratory for New Petro-chemical Materials and Fine Utilization of \\ Resources, College of Chemistry and Chemical Engineering, Hunan Normal University, Changsha, China \\ Email: xuqiong139@126.com, dulinyin@126.com
}

Received February 2014

\begin{abstract}
A carbon-based solid acid with high acid density was successfully prepared using camphor tree branches as raw materials through a novel method including dilute sulfuric acid activation, carbonization in refluxing solvent and sulfonation. Physical characterization was detected to show that the carbon-based acid is amorphous with polycyclic aromatic carbon sheets attached plentiful $-\mathrm{OH},-\mathrm{COOH}$, and $-\mathrm{SO}_{3} \mathrm{H}$ groups. The sulfonic acid density and total acid density of it reached 2.05 $\mathrm{mmol} \cdot \mathrm{g}^{-1}$ and $5.63 \mathrm{mmol} \cdot \mathrm{g}^{-1}$, respectively by acid-base titration. As a solid acid catalyst, it showed excellent performance in the ketalization of cyclohexanone with glycol.
\end{abstract}

\section{Keywords}

\section{Solid Acid Catalysts, Preparation, Biomass, Ketalization}

\section{Introduction}

With the development of green chemistry, solid acid catalysts have received much attention for green catalytic procedures with advantages of no pollution, easy separation and reusability. However, compare with the catalytic activities of traditional protonic acids such as $\mathrm{H}_{2} \mathrm{SO}_{4}$ etc., that of the solid acid catalysts were always not good enough mostly because of the lower acid density and strength. For decades researchers in this field around the world have been committed to improve the acid density and strength as well as the stability of solid acids. In recent years a sulfonated $\left(\mathrm{SO}_{3} \mathrm{H}\right.$-bearing) carbon-based solid acid has been reported to be an efficient solid acid catalyst for many acid-catalyzed reactions [1-3]. This kind of solid acid was usually prepared via carbonization and sulfonation reaction using renewable biomass resources as carbon sources [4,5]. Their good catalytic activity also showed in catalyzing some special significant reactions like biodiesel production [6-9] and hydrolysis of cellulose [10-12]. It must be one of the most important alterative for $\mathrm{H}_{2} \mathrm{SO}_{4}$ in future chemical industry. Though it is, there is still a long way to make it be an efficient and stable solid catalyst for industry application.

In this paper, we report a novel method to synthesize a carbon-based solid acid catalyst with high density of sulfonic acid groups via solvent refluxing carbonization using camphor tree branches as raw materials. As acetalization reaction is a very important reaction in organic synthesis to protect the carbonyl group $[13,14]$ and synthesis of steroids, pharmaceuticals, and fragrances $[15,16]$, catalytic performances of the obtained catalyst was 
detected in catalyzing the ketalization of cyclohexanone with glycol.

\section{Experimental}

\subsection{Reagents and Materials}

The fallen branches from camphor trees were picked up as raw materials for the catalyst preparation. They were washed, dried and cut to be granules. Oleum ( $50 \mathrm{wt} \% \mathrm{SO}_{3}$ ) was purchased from Zhenxing Chemical Regent Ltd. Co. (Shanghai, China, AR). Other reagents (AR) were from local suppliers.

\subsection{Preparation Process}

The catalyst was prepared as follows: $4 \mathrm{~g}$ camphor tree branch was immersed with $8 \mathrm{~g} 10 \%$ sulfuric acid in a $100 \mathrm{ml}$ flask for $24 \mathrm{~h}$. Then $5 \mathrm{ml}$ toluene was added and the mixture was refluxing for $20 \mathrm{~h}$ at appointed temperature to give a black carbonaceous solid. The solid was filtered and washed in boiling water for $3 \mathrm{~h}$ to get rid of residual sulfuric acid and toluene. The obtained camphor tree branch char denoted as CC. The CC $(2 \mathrm{~g})$ was immersed in $16 \mathrm{~g}$ oleum ( $50 \mathrm{wt} \% \mathrm{SO}_{3}$ ) at $80^{\circ} \mathrm{C}$ for $3 \mathrm{~h}$. After sulfonation, the suspension was cool to room temperature and filtered to yield a black precipitate. Finally, the resulting black solid was washed repeatedly with hot distilled water $\left(>80^{\circ} \mathrm{C}\right)$ until impurities such as sulfate ions were no longer detected in the wash water, and then dried completely to obtain sulfonated camphor tree branch char, which denoted as $\mathrm{CC}-\mathrm{SO}_{3} \mathrm{H}$ in this paper.

\subsection{Catalyst Characterization}

Samples before and after sulfonation were characterized to know the structures of CC and CC- $\mathrm{SO}_{3} \mathrm{H}$ and changes happened during the sulfonation process. BET surface area and pore structure were determined by $\mathrm{N}_{2}$ adsorption and desorption at $77 \mathrm{~K}$ using a TriStar 3000 after the samples were degassed in vacuum at $130^{\circ} \mathrm{C}$ overnight. X-ray powder diffraction (XRD) analysis was conducted on DANDONG Y-2000 X-ray Diffractometer using $\mathrm{Cu} K_{\mathrm{a}}$ radiation with a voltage of $40 \mathrm{kV}$. Fourier transform infrared spectrums (FT-IR) of the samples were recorded in the range $400-4000 \mathrm{~cm}^{-1}$ on a Nicolet Avatar $370 \mathrm{FT}$-IR spectrometer using $\mathrm{KBr}$ pellets. Total acid density and sulfonic acid density of CC- $\mathrm{SO}_{3} \mathrm{H}$ were tested by acid-base titration following the reference [11].

\subsection{Catalytic Reaction}

The typical procedure: A cyclohexone $(0.05 \mathrm{~mol}), 8 \mathrm{~mL}$ cyclohexane, ethylene glycol $(0.08 \mathrm{~mol})$ and $\mathrm{CC}-\mathrm{SO}_{3} \mathrm{H}$ (dosage seen Table 2.) were mixed together in a three necked round bottom flask equipped with a magnetic stirrer and a thermometer, and a Dean-Stark apparatus which was constituted with manifold and condenser was used to remove the water continuously from the reaction mixture. The products were analyzed by a gas chromatograph (Agilent 6890N, FID detector) to show cyclohexanone conversion and ketal selectivity.

In order to investigate the reusability of $\mathrm{CC}-\mathrm{SO}_{3} \mathrm{H}$, the used catalyst was collected, washed with ethanol, and dried for the next reaction. In the recycling reaction, catalyst dosage was $0.02 \mathrm{~g}$, and the other conditions were not changed.

\section{Results and Discussions}

\subsection{Catalyst Characterization}

Textures of $\mathrm{CC}$ and CC-SO $\mathrm{S}_{3} \mathrm{H}$ were characterized by Nitrogen adsorption and desorption. BET surface area, total pore volume and BJH average pore size of $\mathrm{CC}$ and $\mathrm{CC}-\mathrm{SO}_{3} \mathrm{H}$ were given in Table 1. Though surface areas of both samples were not large, it was lager after a sulfonation procedure.

Figure 1 showed XRD patterns of $\mathrm{CC}$ and $\mathrm{CC}-\mathrm{SO}_{3} \mathrm{H}$. Typical crystal diffraction peaks were not seen, and the width and weak diffraction peak at $10^{\circ}-30^{\circ}$ in both patterns implied the structures of both samples were amorphous. The process of carbonization of biomass is sophisticated, especially in the presence of sulfuric acid, and many reactions would occur. The cellulose and hemicellulose chains of camphor tree branches may dehydrate. Lignin may polymerize or rearrange. Crystal structure decomposed and amorphous hydrocarbon structure was detected. The diffraction peak at 16, 22, and 25 in the pattern of CC assigned to characteristic diffraction 
peaks of crystalline cellulose were still visible, which implied an incomplete carbonization.

FT-IR analysis helps to identify the carbon skeleton structure and groups attached on it. Figure 2 showed the IR spectrum of the samples. Infrared spectra of samples in $1605 \mathrm{~cm}^{-1}-1460 \mathrm{~cm}^{-1}$ were a group of $\mathrm{C}=\mathrm{C}$ bond stretching vibration peak, which may attribute to the polycyclic aromatic framework structure. And a band at $2930 \mathrm{~cm}^{-1}$ is attributable to saturated C-H stretching vibration, showed that the carbonization incomplete. This band disappeared after sulfonation indicated cellulose chain continue to convert into polycyclic aromatic hydrocarbon structure during sulfonation. These results were accord with the results from XRD analysis. The band $1700 \mathrm{~cm}^{-1}$ were $\mathrm{C}=\mathrm{O}$ stretching vibration peak. And $3500-2500 \mathrm{~cm}^{-1}$ belonged to $\mathrm{O}-\mathrm{H}$ stretching vibration peak. These peaks were seen in spectra showed that there were plentiful of oxygen-containing groups such as phenolic hydroxyl, ester, ether, carbonylic or carboxylic groups in polycyclic aromatic skeleton. In spectrum of

Table 1. Textural properties of CC and $\mathrm{CC}-\mathrm{SO}_{3} \mathrm{H}$.

\begin{tabular}{cccc}
\hline Samples & $\mathrm{S}_{\mathrm{BET}}\left(\mathrm{m}^{2} \cdot \mathrm{g}^{-1}\right)$ & BJH average pore size $(\mathrm{nm})$ & Pore volumn $\left(\mathrm{cm}^{3} \cdot \mathrm{g}^{-1}\right)$ \\
\hline $\mathrm{CC}$ & 3.0 & 25.4 & 0.018 \\
$\mathrm{CC}^{-\mathrm{SO}_{3} \mathrm{H}}$ & 5.3 & 24.1 & 0.018 \\
\hline
\end{tabular}

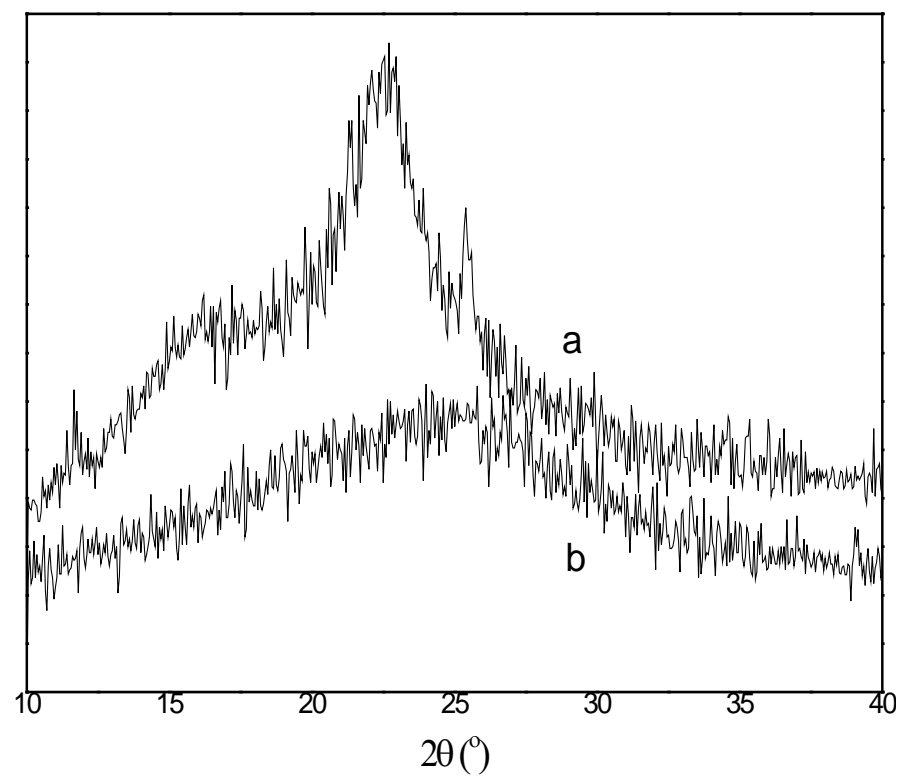

Figure 1. XRD of (a) CC; (b) $\mathrm{CC}-\mathrm{SO}_{3} \mathrm{H}$.

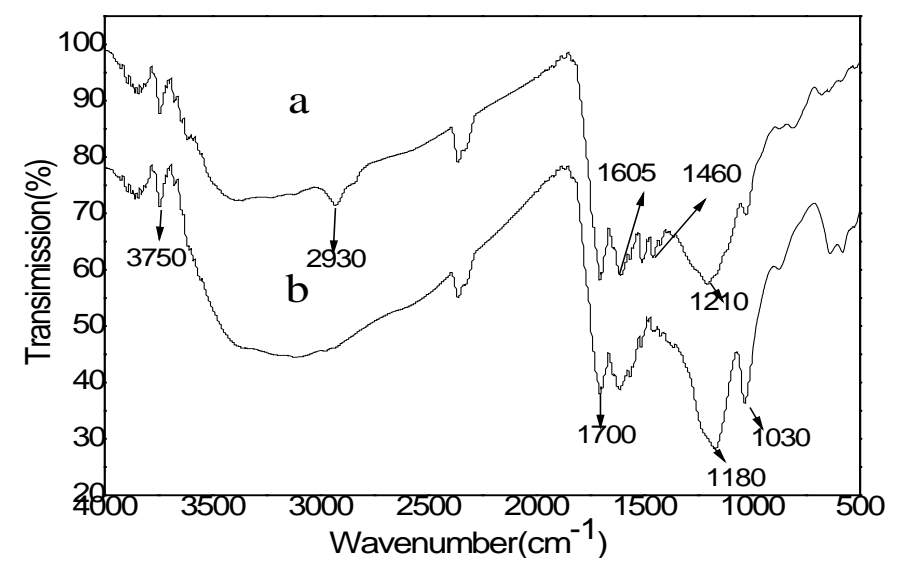

Figure 2. FT-IR patterns of (a) CC; (b) $\mathrm{CC}-\mathrm{SO}_{3} \mathrm{H}$. 
CC- $\mathrm{SO}_{3} \mathrm{H}$, peaks appeared at $1180 \mathrm{~cm}^{-1}$ and $1035 \mathrm{~cm}^{-1}$ assigned to $\mathrm{S}=\mathrm{O}$ double bond stretching vibration, and the characteristic band about $640 \mathrm{~cm}^{-1}$ was the C-S stretching vibration peak. According to the acid-base titration results, sulfonic acid density of CC-SO $\mathrm{SH}_{3}$ was $2.05 \mathrm{mmol} \cdot \mathrm{g}^{-1}$ and the total acid density5.63 $\mathrm{mmol} \cdot \mathrm{g}^{-1}$.

\subsection{Catalytic Activity}

Acetalization is widely applied acid-catalyzed reactions, which are important reaction for protecting the carbonyl group [13,14] and synthesis of intermediates for steroids, pharmaceuticals, fragrance industries [15,16]. Catalytic activity of CC-SO ${ }_{3} \mathrm{H}$ has been evaluated by ketalization of cyclohexanone with ethylene glycol.

Table 2 showed good catalytic activity of $\mathrm{CC}-\mathrm{SO}_{3} \mathrm{H}$ in ketalization of cyclohexanone with ethylene glycol. Few of the catalyst added could dramatically improve cyclohexanone conversation. When the amount of catalyst was $0.05 \mathrm{~g}$, namely account for $0.1 \%$ of cyclohexanone feeding, cyclohexanone conversation reached $92.8 \%$. Furthermore there were no by-products detected in GC analysis.

As reusability of the solid acid was so important, recycling reactions were designed. When the first run was over, the used $0.02 \mathrm{~g}$ catalyst was collected and washed with ethanol for several times. The regenerated catalyst was dried to catalyze the next run. It can reuse at least 6 times with tiny decrease of catalytic activity as shown in Figure 3. That means CC-SO${ }_{3} \mathrm{H}$ can be a good reusable catalyst.

\section{Conclusion}

The high acid density carbon-based solid acid has been synthesized through dilute sulfuric acid activation, solvent refluxing carbonization and sulfonation with camphor tree branch as raw material. And it showed excellent activity and good reusability in catalyzing ketalization of cyclohexanone with ethylene glycol. The catalyst owned advantages of high acidity, high acid density, and high chemical stability, which made it hold great potential for replacement of the homogeneous acid catalysts in the green process. The mild synthesis condition not only reduced cost of the carbon-based solid acid, but also made the industrial production possible.

Table 2. Influences of catalyst dosage on cyclohexanone conversation ${ }^{\mathrm{a}}$.

\begin{tabular}{cc}
\hline Catalyst dosage $(\mathrm{g})$ & Conversation (\%) \\
\hline 0 & 12.0 \\
0.02 & 79.0 \\
0.05 & 92.8 \\
0.10 & 93.4 \\
\hline
\end{tabular}

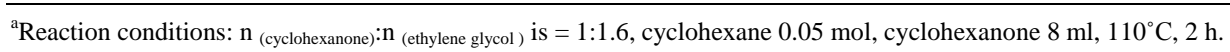

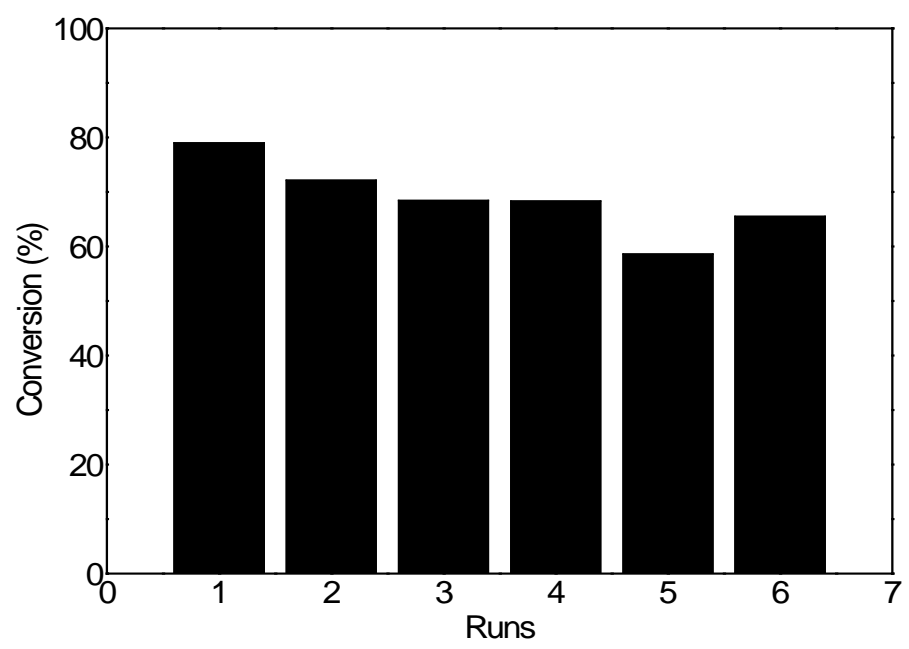

Figure 3. Recycling performance of the $\mathrm{CC}-\mathrm{SO}_{3} \mathrm{H}$. 


\section{Acknowledgements}

Authors thank for support of the National Natural Science Foundation of China (No. 21003043) for this work.

\section{References}

[1] Okamura, M., Takagaki, A. and Toda, M. (2006) Acid-Catalyzed Reactions on Flexible Polycylic Aromatic Carbon in Amorphous Carbon. Chemisty Material, 18, 3039-3045. http://dx.doi.org/10.1021/cm0605623

[2] Dora, S., Bhaskar, T. and Singh, R. (2012) Effective Catalytic Conversion of Cellulose into High Yields of Methyl Glucosides over Sulfonated Carbon Based Catalyst. Bioresource Technology, 120, 318-321.

[3] Xu, Q., Wang, Y.J. and Yin, D.L. (2009) One-Pot Three-component Mannich Reaction Catalyzed by Sucrose Char Sulfonic Acid. Frontiers of Chemical Engineering in China, 3, 201-205. http://dx.doi.org/10.1007/s11705-009-0052-5

[4] Hara, M., Yoshida, T. and Takagaki, A. (2004) A Carbon Material as a Strong Protonic Acid. Angewandte Chemie International Edition, 43, 2955-2958. http://dx.doi.org/10.1002/anie.200453947

[5] Chen, G. and Fang, B.S. (2011) Preparation of Solid Acid Catalyst from Glucose-starch Mixture for Biodiesel Production. Bioresource Technology, 102, 2635-2640. http://dx.doi.org/10.1016/j.biortech.2010.10.099

[6] Yu, J.T., Dehkhoda, A.M. and Ellis, N. (2011) Development of Biochar-based Catalyst for Transesterification of Canola Oil. Energy Fuels, 25, 337-344. http://dx.doi.org/10.1021/ef100977d

[7] Song, X.L., Fu, X.B. and Zhang, Ch.W. (2012) Preparation of a Novel Carbon Based Solid Acid Catalyst for Biodiesel Production via a Sustainable Route. Catalysis Letter, 142, 869-874. http://dx.doi.org/10.1007/s10562-012-0840-2

[8] Chang, B., Tian, Y. and Shi, W. (2013) $\mathrm{SO}_{3} \mathrm{H}$-functionalized Mesoporous Carbon/silica Composite with a Spherical Morphology and Its Excellent Catalytic Performance for Biodiesel Production. Journal of Porous Materials, 20, 14231431. http://dx.doi.org/10.1007/s10934-013-9728-9

[9] Chang, B.B., Fu, J. and Tian, Y.L. (2013) Multifunctionalized Ordered Mesoporous Carbon as an Efficient and Stable Solid Acid Catalyst for Biodiesel Preparation. Journal of Physical Chemistry C, 117, 6252-6258.

[10] Suganuma, S., Nakajima, K. and Kitano, M. (2008) Hydrolysis of Cellulose by Amorphous Carbon Bearing $\mathrm{SO}_{3} \mathrm{H}$, $\mathrm{COOH}$, and OH Groups. Journal of the American Chemistry Society, 130, 12787-12793.

http://dx.doi.org/10.1021/ja803983h

[11] Wu, Y.Y., Fu, Z.H. and Yin, D.L. (2010) Microwave-Assisted Hydrolysis of Crystalline Cellulose Catalyzed by Biomass Char Sulfonic Acids. Green Chemistry, 12, 696-700. http://dx.doi.org/10.1039/b917807d

[12] Zhang, Ch., Fu, Z.H. and Liu, Y.Ch. (2012) Ionic Liqued-Functionalized Biochar Sulfonic Acid as a Biomimetic Catalyst for Hydrolysis of Cellulose and Bamboo under Microwave Irradiation. Green Chemistry, 14, 1928-1934. http://dx.doi.org/10.1039/c2gc35071h

[13] Smith, M.B. (2002) Organic Synthesis. 2nd Ed., McGra-Hill, New York.

[14] Wu, H.H., Yang, F. and Cui, P. (2004) An Efficient Procedure for Protection of Carbonyls in Bronstedacidic Ionic Liquid [Hmim]BF 4 . Tetrahedron Letter, 45, 4963-4965. http://dx.doi.org/10.1016/j.tetlet.2004.04.138

[15] Li, D.M., Shi, F. and Peng, J. (2004) Application of Functinal Ionic Liquids Possessing Two Adjacent Acid Sites for Acetalization of Aldehydes. Journal of Organic Chemistry, 69, 3582-3585. http://dx.doi.org/10.1021/j00348591

[16] Liang, X. and Qi, C. (2011) Synthesis of a Novel Ionic Liquid with Both Lewis and Brønsted Acid Sites and Its Catalytic Activities. Catalysis Communications, 12, 808-812. http://dx.doi.org/10.1016/j.catcom.2011.01.018 